\title{
Liter per Microgram per Meter Squared
}

National Cancer Institute

\section{Source}

National Cancer Institute. Liter per Microgram per Meter Squared. NCI Thesaurus. Code C120812.

A unit of concentration equal to liter divided by microgram per meter squared. 